\title{
A Study on Children's Accessibility Auxiliary Equipment of Ct Machine Based on Emotionalized Design
}

\author{
Bo Mu, Mingguang Cai ${ }^{*}$, Ji Wang \\ Wuhan Institute of Technology, Wuhan, Hubei Province, China \\ *Corresponding author: Mingguang Cai
}

Keywords: Emotionalized design, Pediatric patients, Ct machine, Auxiliary equipment of examination

\begin{abstract}
Under the study background of contemporary children's medical equipment lacking in emotionalized design, this thesis has a systematic study on how auxiliary equipment of CT examination has a positive impact on pediatric patients, in order to make more children do medical examination. Taking pediatric patients' mental feeling in medical treatment as a starting point, it lays more emphasis on emotional needs of pediatric patients, and makes an emotionalized design scientifically from the perspective of children. From the perspective of practice and measure of emotionalized design, the needs of pediatric patients are analyzed and refined in this study, and are classified from three levels of emotionalized design. In addition, according to children's demands in each stage, a design plan is completed in the end. Finally, this article also gives a design innovation trend of medical examination equipment in the future, which should not only meet practical application and emotional need of pediatric patients, but also increase the added value of CT machine, so as to improve the market competitiveness of medical enterprises.
\end{abstract}

\section{Introduction}

Emotionalized design is the core starting point of human emotional needs and the functional basis of product materials. On the premise that the functions of medical devices are completely used, emotionalized design on the form of equipment can make medical products have visual and tactile sense so as to improve users' sense of experience. Emotionalized design of products should not only maintain the rationality of the appearance of products, but also reflect the flexibility of products. That being said, it not only improves the work efficiency of medical staff, but also cares for a lot the inner feelings of pediatric patients.[1] Therefore, it embodies the people-oriented concept in the design. In the past, medical device products were based on simply general human-computer interaction, and thus the interaction between doctors and patients was mainly conducted in the process of using these devices. On the one hand, children are more vulnerable than adults. As pediatric patients are extremely sensitive to the surrounding environment and they cannot properly understand diseases and treatment methods, they cannot remain calm and objective in the face of medical equipment. As a result, pediatric patients may have a certain degree of anxiety or negative attitude towards medical equipment. On the other hand, children grow in an important stage of intellectual and psychological development. If they cannot behave naturally or normally in the face of medical equipment for examination, it will easily give rise to psychological problems. Pediatric patients have not always been in a stable state in the process of conducting medical treatment, and therefore it is also a test for the overall quality of doctors.

Based on above factors, medical equipment design used by pediatric patients as a special group should take fully the characteristics of children into consideration. In other words, it should not only focus on the practicality of products, but also lay an emphasis on physiological needs and psychology of children's medical devices. These elements should be used in the design of emotionalization, in order to reduce children's anxiety and their psychological pressure appropriately, as well as build a bridge of communication between pediatric patients and doctors. In this way can pediatric patients feel comfortable and relaxed in the process of seeking medical helps 
as well as the work efficiency of doctors be improved significantly.[2] The CT machine in a children's hospital in the United States, as shown in Figure1, was designed by an emotionalized design method to improve and optimize the appearance of traditional CT examination. It improves the acceptance of medical equipment in the heart of pediatric patients and reduces their fear and tension in the examining process.

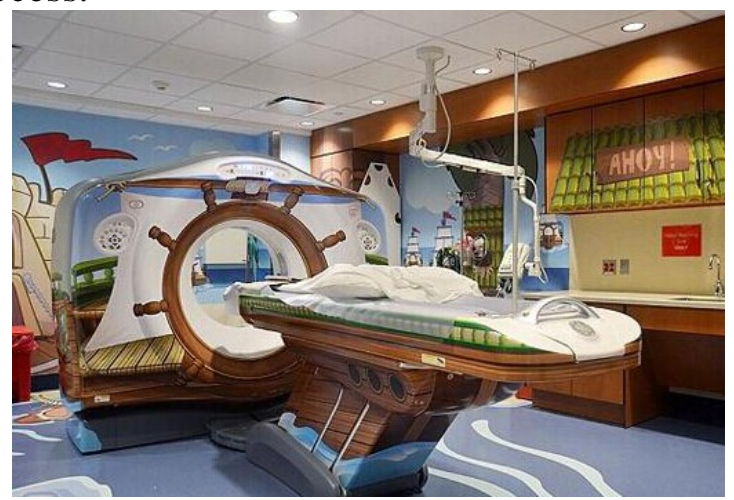

Fig.1 Pirate-Themed Ct Scanner (Image Source: Data)

The design of this CT machine starts from the appearance. First of all, it changes the external image of traditional CT machine and decorates it as a pirate ship. Moreover, on the basis of effective cooperation with doctors, it gradually guides pediatric patients to complete CT examination. By turning a cold and boring CT examination into a ship journey, this design has been greatly improved the quality and efficiency of the examination of pediatric patients.

\section{Psychological Needs of Children}

\subsection{The Appearance Design of Auxiliary Equipment of Ct Machine}

The appearance design should first analyze the characteristics of pediatric patients, and then be taken shape in line with their nature. Children are fond of imitating, playing and being praised. They are full of curiosity, and are innocent and lively. In addition, they find it more difficult to concentrate on one thing and easier to enjoy small animals and cute patterns. Based all above characteristics, it is found that children have less learning abilities, but can carry out some simple object operation. They are more sensitive in this stage, and their emotions are more subtle. They have strong abstract thinking abilities. If the child is full of curiosity and loves to play with everything, this design can be combined with interesting games, and make the child identify himself/herself from the bottom of heart. If the child loves small animals and cute patterns, the appearance of the design modeling should be combined with his/ her favorite cartoon and bionic patterns.[3] If the child likes being praised, this design should increase sound function in order to make the child feel happy, such as praising sound. As a matter of fact, pediatric patients do not have much knowledge, so this design should be simple and easy to use in terms of functional design. Therefore, in the design of auxiliary equipment for CT examination, it is necessary to analyze the preference of pediatric patients and choose reasonable colors to avoid stimulating the inner emotions of pediatric patients.

In addition, children are easy to be scratched with their delicate skins, so in the design of children's accessibility auxiliary equipment of CT examination machine, the safety should be fully considered in the appearance design of products. In the use of products, children can feel safe and comfortable, so as to provide good medical services for such sensitive medical groups as pediatric patients.

\subsection{The Color Design of Auxiliary Equipment of Ct Machine}

According to relevant research data on color psychology, compared with cool colors, pediatric patients prefer low purity and warm colors which can effectively ease the tension of pediatric patients. By choosing appropriate color combination in the CT examination environment, pediatric patients are more likely to feel relax, thus achieving the purpose of cooperating with medical 
examination. This design id dominant in warm color with collocation of other chromatic colors, which makes overall color better arranged in effect. [4]If it is a small medical treatment, this design should choose mainly white with chromatic colors. If it is a major medical treatment, this design should select black, white and gray (partially arranged with chromatic colors but desaturated). In fact, each color has its individual meaning, which can remind the child something different. An appropriate color can give the child a good emotional experience. As it is shown in Table 1, color meaning tells: Red reminds children of the sun, which represents enthusiasm and vitality; blue reminds people of the sky and children of the sea, representing calm and relaxation; green reminds children of trees and grasses, representing relaxation and nature. These positive words are in line with children's outgoing personality and are good for their physical and mental health. Therefore, color design of auxiliary equipment of CT machine should avoid using cold colors, and then make a reasonable color combination of auxiliary equipment of CT machine to narrow the distance between the child and the CT machine, so that children can accept health inspection safely and happily.

Table 1 Color Meanings (Table Source: Painter Works)

\begin{tabular}{|l|l|l|}
\hline Colors & Functions & Imaginations \\
\hline Red & arouses energetic and creative power, represents enthusiasm and vitality. & sun \\
\hline Orange & represents excited, warm, vivid, more participation, stimulates appetite. & fire, sunset \\
\hline Yellow & $\begin{array}{l}\text { represents happy, bright and warm, reduces tension and pressure, gives an alarm } \\
\text { and stimulates digestive system. }\end{array}$ & $\begin{array}{l}\text { lemon,little } \\
\text { duck }\end{array}$ \\
\hline Green & represents relaxed, comfortable, refreshing and clam. & trees, grasses \\
\hline Blue & represents calm and relaxed, lowers blood pressure, eases muscle tension & sky, sea \\
\hline White & $\begin{array}{l}\text { eases muscle tension and pain, makes people clam, eases muscle tension of } \\
\text { patients. }\end{array}$ & clouds, snow \\
\hline Pink & represents lovely, sweet, refreshing, arouses hopes. & $\begin{array}{l}\text { lady,cherry } \\
\text { flower }\end{array}$ \\
\hline
\end{tabular}

Children at different stages have different views and needs on colors. After understanding these characteristics, color should be selected scientifically according to children at a certain age. Table2 lists the color analysis of the three stages, such as infancy, preschool stage and childhood. The design practice is aimed at children between 6 and 12 year-old children who like bright and lively colors. Lively and bright colors can strongly arouse their interest.[5]

Table 2 Color Cognitive Analysis of Children at Different Periods (Table Source: Painter Works)

\begin{tabular}{|l|l|l|l|}
\hline Stages & Psychological characteristics & Favorable color & Design orientation \\
\hline $\begin{array}{l}\text { Infancy (aged } \\
\text { 1 to 3) }\end{array}$ & $\begin{array}{l}\text { Unable to distinguish color, } \\
\text { emotion and psychology of } \\
\text { parents and medical stuff have } \\
\text { a great impact on children's } \\
\text { mental feelings. Color effect is } \\
\text { not significant. }\end{array}$ & $\begin{array}{l}\text { Bright and chromatic colors. } \\
\text { Easier to be loved by female, } \\
\text { such as light blue, light pink, } \\
\text { light yellow, etc. }\end{array}$ & $\begin{array}{l}\text { Color design of infancy } \\
\text { products should be suitable } \\
\text { for need of young } \\
\text { women for colors. }\end{array}$ \\
\hline $\begin{array}{l}\text { Preschool } \\
\text { stage (aged 3 } 3 \text { to 6) }\end{array}$ & $\begin{array}{l}\text { Immature in all aspects, simple } \\
\text { psychological feelings. They } \\
\text { love innocent and bright color } \\
\text { in nature. }\end{array}$ & $\begin{array}{l}\text { They prefer simple and bright } \\
\text { colors, such as, red, blue, green, } \\
\text { etc. they start to like cool colors } \\
\text { since they are 5 years old. }\end{array}$ & $\begin{array}{l}\text { Color design of products } \\
\text { should be applied for pure } \\
\text { color with strong } \\
\text { comparation and } \\
\text { brightness, which are } \\
\text { preferred by children at this } \\
\text { stage. }\end{array}$ \\
\hline $\begin{array}{l}\text { Childhood } \\
\text { (aged 6 to 12) }\end{array}$ & $\begin{array}{l}\text { Well-mature and better } \\
\text { thinking ways, able to take in } \\
\text { new knowledge and chromatic } \\
\text { colors. }\end{array}$ & $\begin{array}{l}\text { Generally, bright, refreshing and } \\
\text { vivid colors are their favorite. } \\
\text { They have their preference to } \\
\text { colors. Boys love more blue and } \\
\text { yellow than red and green, while } \\
\text { girls like more red and yellow } \\
\text { than blue, orange and white. }\end{array}$ & $\begin{array}{l}\text { Color design of products } \\
\text { should be selected } \\
\text { according to boys and girls, } \\
\text { thus offering more choices. }\end{array}$ \\
\end{tabular}




\section{Analysis of Children's Sensory Experience}

Children are the future of the motherland, as well as apples of parents' eyes. Due to delicate and sensitive skins of children, the first requirement of material is avirulent; The second requirement is green and environmental friendly, mainly reflecting in safety and environmental protection. As children have delicate skins, these materials of products should be comfortable, soft and scratch resistant.[6]

\section{Design Orientation}

Through improved design with emotional attachments, the medical examination can reduce the resistance of pediatric patients to medical examination after using, reduce inner pressure of children when conducting medical treatment, and improve the work efficiency of medical staff. The design is conceived through the three dimensions such as vision, touching and hearing can relieve the tension and fear of children in CT examination. Through the combination with animal bionics and cartoon characters, children can reduce their inner resistance and ease their inner tension and fear during CT examination.[7]

\subsection{User-Centered Orientation}

Children should be put as shared users of CT MRI machines in radiology department with adult groups during hospital examinations. There are two groups of people who come into contact with CT examination machine, such as children and health care workers. Children, as the main group, are directly in contact with the CT machine for examination. Due to their limited knowledge level, they do not know about the operation of CT examination machine, but only know that it is a large cold machine, which makes a buzzing sound during the examination, so that they are more likely to feel panic and be at a loss. If not so strong, they might cry aloud. If worse, pediatric patients may be affected seriously in their psychological and intellectual development because of this examination. Psychological resistance seems to greatly increase workload of medical staff and reduced the working efficiency of medical staff. Medical staff as backstage staff, are likely to slacken their high concentration and attention due to mechanical work of CT equipment. When children have these emotions such as fear, panic, bursting into tears, they are unable to conduct examination with the help of medical stuff. It undoubtedly increases physiological stress and psychological pressure of medical staff, thus reducing the inspection efficiency of medical personnel.

Pediatric patients are natural players. As a vulnerable group, children are prone to fear when conducting medical examination, thus leading to the resistance of pediatric patients to medical examination. On the one hand, children are sensitive to color, with ups-and-downs emotions. On the other hand, medical staff has a lot of examination but they should be more careful with a great mental pressure. Furthermore, machine operation is too cumbersome to them. In addition, their comprehensive qualities are excellent, and have a great compassion.[8]

\subsection{Function Orientation}

On the basis of original CT machine, an emotionalized design of auxiliary device (attachment added) is carried out to alleviate the tension, fear and resistance of children, such a sensitive group during CT examination, as shown in Fig. 2.

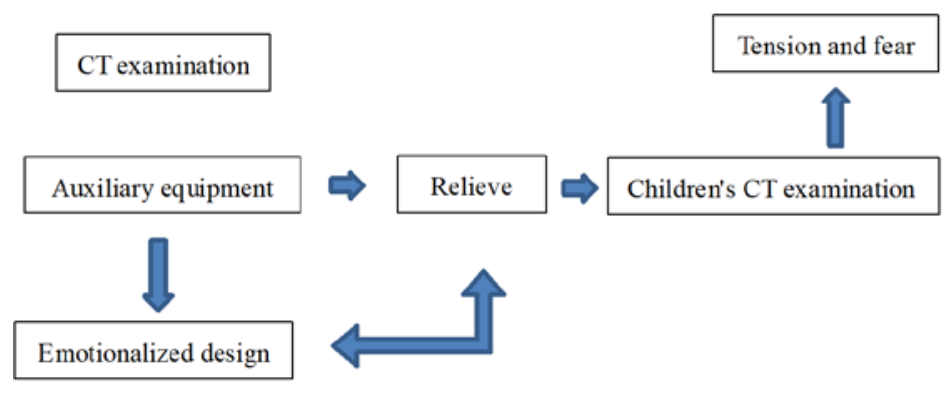

Fig. 2 Function Orientation (Picture Source: Painter Works) 


\subsection{Color Orientation}

According to relevant research data on color psychology, compared with cool colors, pediatric patients prefer low purity and warm colors, which can effectively ease the tension of pediatric patients. By choosing appropriate color combination in CT examination, pediatric patients are more likely to be relaxed, thus achieving the purpose of cooperating with medical examination. The colors are chosen according to animal shapes, making designs more recognizable and acceptable. Matching colors of wooden ladder should be selected according to the matching colors of building blocks, low saturation and low purity colors. Design originates from life and higher than life. So designs should be extracted from design elements of children's toys and cartoons. When children conduct radiologists examination with their familiar things, it will greatly reduce inner strangeness and fear, as well as internal resistance. Based on this, children are more likely to recognize this environment from the bottom of heart, which guides children to do medical checks successfully.

\subsection{Materials Orientation}

Materials of products should be selected with three properties such as non-toxic, safety and comfortable. Children are the successor of the country, as well as the future of the motherland. Parents' apples have a physical sensitivity so the first choice for materials is non-toxic. In addition, green materials are mainly reflected in safety and environmental protection. Finally, children's delicate skin requires comfortable, soft and scratch-resistance products.

\subsection{Modeling Orientation}

Young children are easier to scratch cut deodorant to their soft skins. As a result, auxiliary equipment of CT examination should make a comprehensively scientific design combining cartoon characters and animal bionics with the smoothness of products without sharp feeling. This design should make children feel a sense of security and comfort, in order to relieve their strain, fear and anxiety during CT examination, so as to let children have a good medical service, as shown in Fig. 3 .

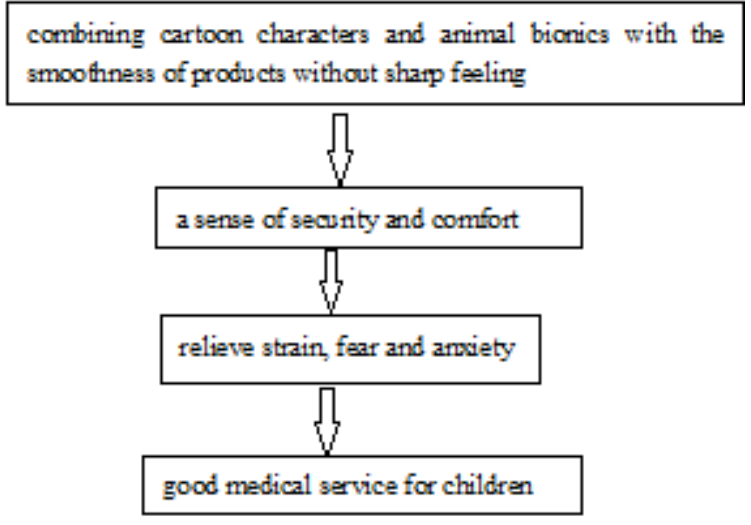

Fig.3 Modeling Orientation (Image Source: Painter Works)

There are four animal models such as panda, monkey, bear and rabbit. They are selected for design and creation. All of them have high image recognition. Designs are combined with children's common images of cartoons and toys, and are integrated with children's childlike world, in order to reduce children's resistance and increase their psychological identity.

\subsection{Design Innovation}

Designs are conceived through the three dimensions such as vision, touching and hearing. Combined with animal bionics and cartoon characters, it can not only help children reduce their inner resistance but also ease their inner tension and fear during CT examination. In the sense of vision, it is expressed by colors and forms. In terms of colors, it selects lower brightness and purity. In terms of forms, it chooses mellow, safe, soft and assured shapes. In the sense of touch, it is 
presented by texture. It selects frosted, smooth, soft, safe, non-toxic, green and recyclable materials. In the sense of hearing, it is presented by sound. Greetings and situational stories are selected in terms of sound.

(When the child comes to the radiology department for examination,)

1). There Will Be Voice Prompts to Let the Child to Operate by Herself/ Himself (a Sense of Participation);

2). The Doctor Will Ask the Child Which Animal-Shaped Ct Examination Auxiliary Device he/She Likes, and the Child Can Choose by Himself (a Sense of Participation);

3). there will be voice prompts to let the child to open the accumulated wooden ladder and go to examination bed. When the child opens the accumulated wooden ladder, the built-in projection device will make forest scene for the child (shadow puppetry projection principle);

4). The Child Will Get on the Examination Bed, Lie in the Arms of the Animal-Shaped Auxiliary Device of Ct Examination Selected by Himself/Herself, and Conduct the Exploration of Ct Examination.

5). The Child Will Leave after Checking.

Based on these designs, children can have a sense of participation. These designs can reduce the inner resistance of children, so as to better match and complete the examination with doctors. (design sketch is shown in Fig. 4)

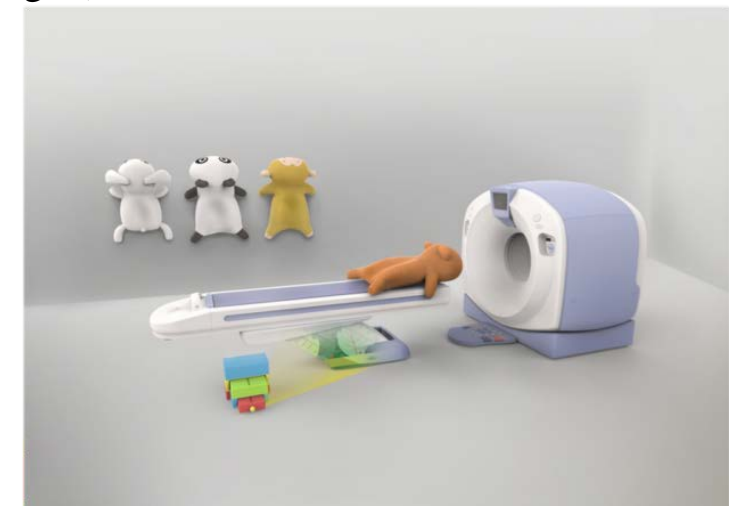

Fig.4 Overall Design Sketch (Image Source: Painter Works)

\section{Conclusion}

As a vulnerable group, children urge to be paid more attention to their mental health needs. The emotionalized design is scientifically applied to children's auxiliary equipment of CT examination. On the basis of the integrity of diagnosis and treatment process, this design is measured by the behavioral characteristics and psychological characteristics of children, so as to increase the tension and affinity of the cold medical products and enable children to have a pleasant spiritual experience in the process of seeking medical treatment. By adding examination attachment of emotionalized design, children and adult patients can reasonably use same CT examination equipment without affecting the examination process. As a result, there is no need to open an examination room for children alone. This combination of modular design to a certain extent reduces waste of resources, which makes medical resources more reasonably and effectively applied. Emotionalized design has become an important development trend of modern design, especially medical product design. The emotionalized design applied to the product design of auxiliary equipment of CT examination, which not only meets the needs of pediatric patients in terms of use and emotion, but also increases the added value of CT machine.

\section{Acknowledgement}

Project: 2019-2020 Hubei Provincial Project of Youth Work Research Association,Project No.: GYHYB2019020; Project: 2018 Hubei Provincial University Practice and Educating Characteristic Project, "Morality and Art Enactus” Volunteer Service Growth Plan, Project No.: 2018SJJPD3015. 


\section{References}

[1] Yu, H. Research on Emotionalized Design of Medical Atomizer for Children, Harbin University of Science and Technology, 2018.

[2] Shi, Y.J., Yu, H., Yao, J. Application Research of Bionics in Emotionalized Design of Children's Medical Products. Design, no. 03, pp. 34-35, 2018.

[3] Yin, L.L. Research on Children's Toy Design Based on Cartoon Image, Hubei University of Technology, 2017.

[4] Liu, J. Research on Emotionalized Design of Children's Handheld Atomizer, Hubei University of Technology, 2017.

[5] Man, D., Wei, D. Product Color Emotional Design Considering Color Layout. Color Research \&Application, no. 44, pp. 2, 2019.

[6] Li, Y. Research on Monitor Design Based on Emotionalized Design, Shandong University, 2014.

[7] Zhang, X.P., Zhang, M.Y. Emotionalized Design of Medical Devices. Packaging Engineering, no. 06, pp. 157-159, 2008.

[8] Zhang, Q. Research on User-centered Emotional Interaction Design, Nanjing University of Aeronautics and Astronautics, 2007. 